Article

\title{
Preparation and Evaluation of Resveratrol-Loaded Composite Nanoparticles Using a Supercritical Fluid Technology for Enhanced Oral and Skin Delivery
}

\author{
Eun-Sol Ha ${ }^{1}$, Woo-Yong Sim ${ }^{1}$, Seon-Kwang Lee ${ }^{1}$, Ji-Su Jeong ${ }^{1}$, Jeong-Soo Kim ${ }^{2}$, \\ In-hwan Baek ${ }^{3}{ }^{D}$, Du Hyung Choi ${ }^{4}$, Heejun Park ${ }^{5}$, Sung-Joo Hwang ${ }^{6} \mathbb{D}$ and Min-Soo Kim ${ }^{1}$,* \\ 1 College of Pharmacy, Pusan National University, 63 Busandaehak-ro, Geumjeong-gu, Busan 46241, Korea; \\ edel@pusan.ac.kr (E.-S.H.); popo923@pusan.ac.kr (W.-Y.S.); lsk7079@pusan.ac.kr (S.-K.L.); \\ sui15@pusan.ac.kr (J.-S.J.) \\ 2 Dong-A ST Co. Ltd., Giheung-gu, Yongin, Gyeonggi 446-905, Korea; ttung2nd@naver.com \\ 3 College of Pharmacy, Kyungsung University, 309, Suyeong-ro, Nam-gu, Busan 48434, Korea; baek@ks.ac.kr \\ 4 Department of Pharmaceutical Engineering, Inje University, Gyeongnam 621-749, Korea; choidh@inje.ac.kr \\ 5 Department of Industrial and Physical Pharmacy, College of Pharmacy, Purdue University, 575 Stadium Mall \\ Drive, West Lafayette, IN 47907, USA; pharmacy4336@gmail.com \\ 6 College of Pharmacy and Yonsei Institute of Pharmaceutical Sciences, Yonsei University, \\ 85 Songdogwahak-ro, Yeonsu-gu, Incheon 21983, Korea; sjh11@yonsei.ac.kr \\ * Correspondence: minsookim@pusan.ac.kr; Tel.: +82-51-510-2813
}

Received: 2 November 2019; Accepted: 13 November 2019; Published: 14 November 2019

\begin{abstract}
We created composite nanoparticles containing hydrophilic additives using a supercritical antisolvent (SAS) process to increase the solubility and dissolution properties of trans-resveratrol for application in oral and skin delivery. Physicochemical properties of trans-resveratrol-loaded composite nanoparticles were characterized. In addition, an in vitro dissolution-permeation study, an in vivo pharmacokinetic study in rats, and an ex vivo skin permeation study in rats were performed. The mean particle size of all the composite nanoparticles produced was less than $300 \mathrm{~nm}$. Compared to micronized trans-resveratrol, the trans-resveratrol/hydroxylpropylmethyl cellulose (HPMC)/poloxamer 407 (1:4:1) nanoparticles with the highest flux $\left(0.792 \mu \mathrm{g} / \mathrm{min} / \mathrm{cm}^{2}\right)$ exhibited rapid absorption and showed significantly higher exposure $4 \mathrm{~h}$ after oral administration. Good correlations were observed between in vitro flux and in vivo pharmacokinetic data. The increased solubility and flux of trans-resveratrol generated by the HPMC/surfactant nanoparticles increased the driving force on the gastrointestinal epithelial membrane and rat skin, resulting in enhanced oral and skin delivery of trans-resveratrol. HPMC/surfactant nanoparticles produced by an SAS process are, thus, a promising formulation method for trans-resveratrol for healthcare products (owing to their enhanced absorption via oral administration) and for skin application with cosmetic products.
\end{abstract}

Keywords: resveratrol; solubility; nanoparticle; correlation; supercritical fluid; bioavailability

\section{Introduction}

Trans-resveratrol is abundant in various foods, such as grapes, peanuts, and berries, and is usually taken as a dietary supplement. Chemically, trans-resveratrol is known as 3,5,4'-trihydroxystilbene, a non-flavonoid polyphenolic compound produced by plants in response to injury or attack by bacteria and fungi [1]. When exposed to UV light, the typically low transformation of trans-resveratrol to cis-resveratrol is accelerated [2]. Trans-resveratrol has been shown to have several beneficial properties, including anti-aging, anticancer, antidiabetic, anti-inflammatory, antioxidant, cardioprotective, and neuroprotective activities [3-6]. Unfortunately, due to its poor water solubility, 
instability, short plasma half-life, and extensive metabolism in the intestine and liver, clinical uses of trans-resveratrol are limited to oral administration [1,7-9]. Trans-resveratrol is a Biopharmaceutical Classification System (BCS) class II compound with an insolubility in aqueous solutions of pH 1.0 to pH 7.5 and high permeability [1]. Due to these properties, trans-resveratrol is quickly metabolized, therefore skin application may be an alternative to oral administration [10-12]. Various formulation strategies, including the use of liposomes, solid dispersions, cyclodextrin complexes, solid lipid nanoparticles, emulsions, polymeric micelles, polymeric nanoparticles, and nanocrystals, have been evaluated to attempt to overcome current limitations of trans-resveratrol [13-21]. In particular, a pharmacokinetic study of twelve healthy volunteers given an oral administration of a capsule formulation of resveratrol via solubilization with micelles consisting of polysorbate 80, polysorbate 20 , and medium chain triacylglycerol yielded increases in the area under the plasma concentration versus time curve $(A U C)$ and maximum plasma concentration $\left(C_{\max }\right)$ of resveratrol of 5.0 -fold and 10.6-fold, respectively, compared to volunteers ingesting a resveratrol powder [19]. In a study with rabbits, a solid dispersion of resveratrol produced an AUC value that was 3-fold higher compared to rabbits who ingested a resveratrol/magnesium dihydroxide solid dispersion [20]. However, in a study of resveratrol and piperine cocrystals, concentration of resveratrol in saturated solution at various conditions was decreased compared to pure resveratrol, resulting in decreased oral bioavailability [21]. It is, thus, critical to enhance the in vitro solubility and dissolution properties of resveratrol to improve its absorption by the body, and thus increase its biological performance [22,23].

We hypothesize that the rapid dissolution rate and high degree of supersaturation (solubility) of trans-resveratrol formulated with amorphous composite nanoparticles is directly related to increases in trans-resveratrol absorption. In this study, composite nanoparticles containing hydrophilic additives were produced using the supercritical antisolvent (SAS) process to increase the solubility and dissolution properties of trans-resveratrol for application by oral and skin delivery. Supercritical carbon dioxide $\left(\mathrm{SC}-\mathrm{CO}_{2}\right)$ was used as an antisolvent, and it has significant safety advantages. The airborne concentration at $25^{\circ} \mathrm{C}$, considering a high threshold limit value (TLV) of $5000 \mathrm{ppm}$, is a safe environment that a workforce may be exposed to daily without adverse effects. In addition, $\mathrm{SC}-\mathrm{CO}_{2}$ is highly dense, permeable, has a high solvent power and diffusion rate, and is usually miscible with organic solvents [24]. These properties can cause a higher supersaturation during the SAS process, hence reducing the critical energy barrier for nucleation, which leads to faster nucleation, and therefore the precipitation of more and smaller particles [25]. Physicochemical characterization of composite nanoparticles was carried out using particle size and specific surface measurements, scanning electron microscopy, powder X-ray diffraction, differential scanning calorimetry, and kinetic solubility analysis. In addition, an in vitro dissolution-permeation study was performed to compare the trans-resveratrol flux of different composite nanoparticles prepared by an SAS process. An in vivo pharmacokinetic study in rats was also performed. We also investigated the correlation between in vitro flux data and in vivo pharmacokinetic data on trans-resveratrol. Finally, we performed ex vivo skin permeation studies using rats to investigate the use of trans-resveratrol-loaded composite nanoparticles for skin delivery.

\section{Materials and Methods}

\subsection{Materials}

Trans-resveratrol was supplied by Ningbo Liwah Pharmaceutical Co., Ltd. (Zhejiang, China), and micronized to a mean particle size of $2.6 \mu \mathrm{m}$ and purity of $99.1 \%$ by using an air jet mill. Polyvinylpyrrolidone K 12/25/30/90 (PVP K12/K25/K30/K90), polyvinylpyrrolidone vinyl acetate 64 (PVP VA 64), polyvinyl caprolactampolyvinyl acetate-polyethylene glycol graft copolymer (Soluplus ${ }^{\circledR}$ ), macrogol (15)-hydroxystearate (Kolliphor ${ }^{\mathrm{TM}}$ HS 15), D- $\alpha$-Tocopherol polyethylene glycol 1000 succinate (TPGS), and poly (ethylene glycol)-block-poly (propylene glycol)-block-poly(ethylene glycol) (Poloxamer 188/407) were obtained from BASF (Ludwigshafen, Germany). Hydroxylpropylmethyl cellulose (HPMC $3 \mathrm{cp} / 4.5 \mathrm{cp} / 6 \mathrm{cp}$ ) and low viscosity hydroxylpropyl 
cellulose (HPC-SSL) were provided by Shin-Etsu chemical Co., Ltd. (Tokyo, Japan), and Nippon Soda Co., Ltd. (Japan), respectively. Polyethylene glycol 6000, sodium carboxymethylcellulose (CMC), and sodium lauryl sulfate (SLS) were purchased from Sigma-Aldrich Co., Ltd. (St. Louis, MO, USA). Sucrose laurate (Ryoto ${ }^{\mathrm{TM}}$ Ester L-1695, Mitsubishi-Kagaku Foods Co., Tokyo, Japan) was gifted by Namyung commercial Co., Ltd. (Seoul, Korea). Sorbitan monolaurate (Span ${ }^{\circledR}$ 20), sorbitan monostearate $\left(\operatorname{Span}^{\circledR}{ }^{\circledR} 60\right)$, sorbitan monooleate (Span ${ }^{\circledR} 80$ ), and polysorbate 20/60/80 (Tween ${ }^{\circledR}$ 20/60/80) were purchased from Daejung Chemicals and Metals Co., Ltd. (Siheung-si, Korea). Propylene glycol dicaprolate/dicaprate (Labrafac ${ }^{\mathrm{TM}}$ PG, Gattefossè, Saint-Priest, France), medium chain triglycerides (Labrafac ${ }^{\mathrm{TM}}$ Lipophile WL1349, Gattefossè, Saint-Priest, France), oleoyl polyoxyl-6 glycerides (Labrafil ${ }^{\circledR}$ M 1944CS, Gattefossè, Saint-Priest, France), linoleoyl polyoxyl-6 glycerides (Labrafil ${ }^{\circledR}$ M 2125CS, Gattefossè, Saint-Priest, France), lauroyl polyoxyl-6 glycerides (Labrafil ${ }^{\circledR} \mathrm{M}$ 2130CS, Gattefossè, Saint-Priest, France), caprylocaproyl polyoxyl-8 glycerides (Labrasol ${ }^{\circledR}$, Gattefossè, Saint-Priest, France), propylene glycol monolaurate type II (Lauroglycol ${ }^{\mathrm{TM}}$ 90, Gattefossè, Saint-Priest, France), and polyglyceryl-3 dioleate (Plurol ${ }^{\circledR}$ Oleique CC 497, Gattefossè, Saint-Priest, France) were kindly provided by Masung Chemicals (Seoul, Korea). All organic solvents and reagents used were either of high-performance liquid chromatography (HPLC) grade or analytical grade and were purchased from Honeywell Burdick and Jackson (Muskegon, MI, USA) or Daejung Chemicals and Metals Co., Ltd. (Siheung-si, Korea), respectively.

\subsection{Solubility Studies of Trans-Resveratrol in Aqueous Solutions Containing Various Additives}

The solubility of trans-resveratrol in aqueous solutions was measured to test different polymers and surfactants. First, aqueous solutions containing $1 \%$ polymer or $1 \%$ surfactant $(\mathrm{w} / \mathrm{v})$ were prepared and excess resveratrol was added to an amber vial containing $10 \mathrm{~mL}$ of each solution. Samples were sonicated for $1 \mathrm{~h}$ then incubated in a shaking water bath at $37^{\circ} \mathrm{C}$ for $72 \mathrm{~h}$ to reach equilibrium. Next, samples were centrifuged at $12,000 \times g$ for $15 \mathrm{~min}$ and filtered through a $0.2 \mu \mathrm{m}$ glass fiber syringe filter. Then, $1 \mathrm{~mL}$ of filtrate was taken into an amber volumetric flask and diluted with methanol. The concentration of resveratrol was then determined using a Shimadzu HPLC system (Shimadzu, Tokyo, Japan) consisting of an SPD-20A ultraviolet-visible (UV/VIS) detector, CBM-20A communications bus module, SIL-20AC autosampler, LC-20AT liquid chromatograph, DGU-20A 5R degassing unit, and a C18 analytical column $(4.6 \times 150 \mathrm{~mm}, 5 \mu \mathrm{m}$, Shiseido, Tokyo, Japan). HPLC analysis conditions were as follows: a $40 \%$ acetonitrile in water mobile phase, $0.8 \mathrm{~mL} / \mathrm{min}$ flow rate, $30{ }^{\circ} \mathrm{C}$ column temperature, $10 \mu \mathrm{L}$ injection volume, and UV detector wavelength of $303 \mathrm{~nm}$.

\subsection{Nanoparticle Preparation Using an SAS Process}

For preparation of trans-resveratrol-loaded composite nanoparticles, an SAS process was applied using the equipment as previously described [26,27]. $\mathrm{CO}_{2}$ gas was liquefied using a cooler, raised to the required temperature using a heat exchanger, and was pumped through an ISCO ${ }^{\mathrm{TM}}$ pump (Model 260D, Teledyne Technologies Inc., Thousand Oaks, CA, USA) into a high-pressure precipitation vessel. Alongside an SAS process, drug solutions were prepared by dissolving resveratrol/polymer (HPMC 6 cp)/surfactant (gelucire 44/14, TPGS, or poloxamer 407)) in a mixture of methanol and dichloromethane $(1: 1, \mathrm{w} / \mathrm{w})$ in an amber vial. When the system reached a certain temperature and pressure $\left(40{ }^{\circ} \mathrm{C}\right.$ and $\left.12 \mathrm{MPa}\right)$, the drug solution was injected through the nozzle into a high-pressure vessel at a constant rate $(1 \mathrm{~g} / \mathrm{min})$, along with supercritical carbon dioxide $(40 \mathrm{~g} / \mathrm{min})$. The temperature of the precipitation vessel was maintained by circulating water with a temperature-controlled bath circulator. After injection of the drug solution was complete, additional carbon dioxide was applied to remove residual solvent dissolved in supercritical carbon dioxide. The pressure in the precipitation vessel was then slowly reduced to atmospheric pressure using the back-pressure regulator and the precipitated particles inside the vessel were collected. 


\subsection{Trans-Resveratrol Content Analysis}

Levels of trans-resveratrol within the composite particles were determined using HPLC analysis of sample solutions. Composite particles were dissolved in a mixture of methanol and dichloromethane $(1: 1, w / w)$. After dilution with methanol, the concentration of trans-resveratrol was determined using a Shimadzu Prominence HPLC system (Shimadzu, Tokyo, Japan). The encapsulation efficiency (\%) was calculated by dividing the measured concentration by the theoretical concentration and then multiplying this by 100 .

\subsection{Scanning Electron Microscopy (SEM)}

The morphology of the samples was examined using a scanning electron microscope (SUPRA 25 or 40, Zeiss, Oberkochen, Germany) operating at a voltage of $5 \mathrm{kV}$. Before observation, samples were fixed to aluminum stubs with double-sided adhesive carbon tape and then gold coated at a pressure of 8-10 Pa for $1 \mathrm{~min}$ to increase electrical conductivity of the sample.

\subsection{Particle Size Measurements}

The average particle size of the samples was determined with dynamic light scattering (ELSZ-1000, Otsuka Electronics, Tokyo, Japan). Samples were sufficiently dispersed in mineral oil and sonicated for $10 \mathrm{~min}$, then size measurements performed at least four times.

\subsection{Specific Surface Area Measurements}

The specific surface area of composite nanoparticles was measured with a Micromeritics TriStar II 3020 instrument (Micromeritics, Norcross, GA, USA), using the adsorption of nitrogen at the temperature of liquid nitrogen.

\subsection{Differential Scanning Calorimetry (DSC)}

DSC analysis was performed using a thermal analyzer (DSC25, TA instruments, Inc., New Castle, DE, USA). Prior to each analysis, temperature and heat capacity calibration were performed using high purity indium and aluminum oxide sapphire, respectively, with a temperature range of 0 to $390^{\circ} \mathrm{C}$, a modulation rate of $0.6^{\circ} \mathrm{C} /$ min every $40 \mathrm{~s}$, and a scan speed of $5{ }^{\circ} \mathrm{C} / \mathrm{min}$. Next, $2-4 \mathrm{mg}$ of sample was weighed and placed in a pre-weighed aluminum hermetic pan, then sealed with an aluminum cover. Closed, empty aluminum pans were used as reference samples. Analysis was carried out by heating samples from 0 to $350^{\circ} \mathrm{C}$ at a heating rate of $10^{\circ} \mathrm{C} / \mathrm{min}$ under a nitrogen purge of $400 \mathrm{~mL} / \mathrm{min}$.

\subsection{Powder X-ray Diffraction (PXRD)}

Powder X-ray diffraction analysis for samples was performed from $5^{\circ}$ to $60^{\circ}$ using an X-ray Diffractometer (Xpert 3, Panalytical, Almelo, Netherlands) with Ni-filtered Cu-K $\alpha$ radiation. Data were collected at a scanning speed of $3^{\circ} / \mathrm{min}$ and a step size of 0.01 .

\subsection{Kinetic Solubility Study}

A sample of $100 \mathrm{mg}$ trans-resveratrol was placed in a water-jacked beaker containing $50 \mathrm{~mL}$ of distilled water maintained at $37^{\circ} \mathrm{C}$ with magnetic stirring at $300 \mathrm{rpm}$. At predetermined time intervals, $3 \mathrm{~mL}$ of sample was withdrawn from the medium and centrifuged at $12,000 \times \mathrm{g}$ for $15 \mathrm{~min}$, then filtered using a $0.2 \mu \mathrm{m}$ glass fiber syringe filter to remove insoluble material. After dilution with methanol, the concentration of trans-resveratrol was quantified using HPLC analysis. All sample measurements were repeated six times.

\subsection{Flux Measurements via In Vitro Dissolution and Permeation Studies}

To compare trans-resveratrol flux between different composite nanoparticles prepared by an SAS process and to evaluate the correlation between in vitro flux data and in vivo pharmacokinetic 
data for trans-resveratrol, a flux measurement study of trans-resveratrol was carried out using a miniaturized dissolution-permeation apparatus ( $\mu$ FLUX ${ }^{\mathrm{TM}}$ apparatus, Pion Inc., Billerica, MA, USA) [28]. This apparatus contains a horizontal diffusion cell composed of a donor cell, membrane, and receiver cell. The membrane (diffusion area of $1.54 \mathrm{~cm}^{2}$ ) used to separate the donor and receiver cells was prepared by impregnating support material (polyvinylidenfluoride, $0.45 \mu \mathrm{m}$ pore size, $70 \%$ porous, $120 \mu \mathrm{m}$ thickness) with $50 \mu \mathrm{L}$ of $\mathrm{GIT}^{\mathrm{TM}}$ lipid solution consisting of $20 \%$ phospholipid in a dodecane lipid solution (Pion Inc., Billerica, MA, USA). The donor cell was filled with $16 \mathrm{~mL}$ of simulated intestinal fluid ( $\mathrm{pH}$ 6.8, with pancreatin), while the receiver cell was filled with $16 \mathrm{~mL}$ of acceptor sink buffer (ASB, Pion Inc., Billerica, MA, USA), consisting of a hydroxyethyl piperazine ethane sulfonicacid (HEPES)-based pH 7.4 buffer containing surfactant micelles to ensure the sink condition of trans-resveratrol. The temperature of the diffusion cell was maintained at $37^{\circ} \mathrm{C}$ by circulating water through the heating block with a temperature bath circulator. A $32 \mathrm{mg}$ sample of trans-resveratrol was placed in the donor cell with magnetic stirring at $150 \mathrm{rpm}$. The concentration of drug in both the donor cell and receiver cell was quantified using UV fiber optic probes $(2 \mathrm{~mm}$ path length for the donor cell and $20 \mathrm{~mm}$ path length for the receiver cell) connected with Pion Rainbow spectrometers, using a wavelength of $306 \mathrm{~nm}$. Data were collected every $1 \mathrm{~min}$ for the first $30 \mathrm{~min}$, then every $5 \mathrm{~min}$ for the next $240 \mathrm{~min}$. The calibration curve for trans-resveratrol levels in simulated intestinal fluid ( $\mathrm{pH}$ 6.8, with pancreatin) in the donor cell was generated by diluting a stock solution of trans-resveratrol in a mixture of ethanol and simulated intestinal fluid at $\mathrm{pH} 6.8$ (with pancreatin). The calibration curve for trans-resveratrol levels in the receiver cell was generated using serial dilutions of a stock solution of trans-resveratrol in acceptor sink buffer. All sample tests were repeated four times. Flux $(J)$, the mass transfer through the membrane, is calculated using Equation (1):

$$
J=\frac{d m}{S d t}=\frac{V}{S} \cdot \frac{d c}{d t}
$$

where $d c / d t$ is the slope of the concentration of trans-resveratrol vs. the time profile in the range with linear slope (except for lag time), $V$ is the volume $(\mathrm{mL})$ of medium in the donor cell, and $S$ is the permeation area $\left(\mathrm{cm}^{2}\right)$.

\subsection{Pharmacokinetic Study of Oral Delivery in Rats}

The animal study protocol is in compliance with institutional guidelines for the care and use of laboratory animals and was approved by the ethics committee of Kyungsung University (No. 17-004A). To investigate the oral bioavailability of trans-resveratrol composite nanoparticles, the in vivo pharmacokinetics of trans-resveratrol in male Sprague-Dawley (SD) rats were evaluated. Thirty-six male SD rats (200 \pm 10 g; Hyochang Science, Daegu, Korea) were divided into six treatment groups of six rats each. The six experimental groups received either micronized trans-resveratrol, trans-resveratrol/HPMC composite nanoparticles (1:4 or 1:5), or trans-resveratrol/HPMC/surfactant composite nanoparticles (1:4:1) at trans-resveratrol doses of $20 \mathrm{mg} / \mathrm{kg}$ by oral administration. Samples were dispersed in $1 \mathrm{~mL}$ of water immediately prior to oral dosing. Blood samples (approximately $0.25 \mathrm{~mL}$ each) were collected in heparinized tubes from the jugular vein of the treated rats at $0.25,0.5,0.75,1,1.5,2,4,6,8$, and 12 $\mathrm{h}$ after dosing. Blood samples were centrifuged at $12,000 \times \mathrm{g}$ for $10 \mathrm{~min}$ at $4{ }^{\circ} \mathrm{C}$. The amount of trans-resveratrol in plasma was determined using HPLC, following a previously reported analytical method [29]. Data were then used to determine the maximum plasma concentration of trans-resveratrol $\left(C_{\max }\right)$, and the time required to reach $C_{\max }\left(T_{\max }\right)$ and the area under the plasma concentration versus time curve $\left(A U C_{0 \rightarrow 12 \mathrm{~h}}\right)$ were calculated using the linear trapezoidal method.

\subsection{Ex Vivo Skin Permeation Study of Skin Delivery}

For application of trans-resveratrol-loaded composite nanoparticles in skin delivery, ex vivo skin permeation studies were carried out for $24 \mathrm{~h}$ at $32{ }^{\circ} \mathrm{C}$ with vertical static-type Franz diffusion cells, using the skin of SD rats as the diffusion membrane. Firstly, after anesthesia, rat abdominal 
skin was shaved using electric and hand razors, then removed surgically. Skin samples were then cleaned of adherent subcutaneous fat and immersed in cold normal saline solution ( $\mathrm{pH}$ 7.4) for $2 \mathrm{~h}$. Powdered samples of trans-resveratrol-loaded composite nanoparticles were placed on the skin membrane surfaces, with effective diffusion areas of $1.86 \mathrm{~cm}^{2}$. Skin membrane surfaces and sampling ports were later covered with parafilm and aluminum foil to minimize the influx of the external compounds and the degradation of trans-resveratrol from light. The loading dose of trans-resveratrol was $0.5 \mathrm{mg} / \mathrm{cm}^{2}$ [30] The receptor cell was filled with $11.5 \mathrm{~mL}$ of a $60: 40$ mixture of phosphate-buffered saline ( $\mathrm{pH}$ 7.4) and ethanol and stirred with a magnetic bar at $150 \mathrm{rpm}$ to ensure uniform mixing. At predetermined time intervals, $0.2 \mathrm{~mL}$ of receptor medium was taken from the receptor compartment and replaced by an equal volume of fresh medium $\left(32{ }^{\circ} \mathrm{C}\right)$. Samples were then centrifuged for $15 \mathrm{~min}$ at $12,000 \times g$, and a $10 \mu \mathrm{L}$ aliquot of the supernatant was injected into an HPLC system, as described above. The amount of trans-resveratrol permeated per unit area of the skin was then calculated. All sample tests were repeated six times.

\subsection{Data Analysis}

Data are expressed as mean \pm standard deviation ( $n=4$ or 6$)$. To evaluate the statistical significance of differences between groups, one-way ANOVA was carried out, followed by least significant difference (LSD) and Student-Newman-Keuls (SNK) tests using SPSS 25.0 software (IBM SPSS Statistics, IBM Corporation, Armonk, NY, USA).

\section{Results and Discussions}

Trans-resveratrol-loaded composite nanoparticles were prepared using an SAS process with hydrophilic polymers and surfactants. For a preliminary study of various additives, the equilibrium solubility of trans-resveratrol in aqueous solutions containing $1 \%$ additive were determined at $37^{\circ} \mathrm{C}$ and are presented in Figure 1. The solubility of trans-resveratrol was $55.3 \mu \mathrm{g} / \mathrm{mL}$ in water, $52.3 \mu \mathrm{g} / \mathrm{mL}$ in $\mathrm{pH} 1.2$ buffer solution, $53.7 \mu \mathrm{g} / \mathrm{mL}$ in $\mathrm{pH} 4.0$ buffer solution, and $51.1 \mu \mathrm{g} / \mathrm{mL}$ in $\mathrm{pH} 6.8$ buffer solution. These results indicate that the solubility of trans-resveratrol is very poor in aqueous solution and is similar to previously reported data [31]. Among the hydrophilic polymers, trans-resveratrol showed the highest solubility in HPMC (6 cp). Interestingly, the solubility of trans-resveratrol increased with increasing viscosity of HPMC, while trans-resveratrol solubility showed the opposite trend in PVP. Surfactants dramatically increased trans-resveratrol solubility via micelle formation. The most effective surfactant tested was poloxamer 407 , followed by TPGS, tween, and gelucire $44 / 14$. The solubility of trans-resveratrol with poloxamer 407 was approximately 20 -fold the solubility of trans-resveratrol alone. Based on the solubility tests, HPMC (6 cp) was selected as the polymer for nanoparticle construction and poloxamer 407, TPGS, and gelucire 44/14 were evaluated as surfactants for preparation of trans-resveratrol-loaded composite nanoparticles using an SAS process. 


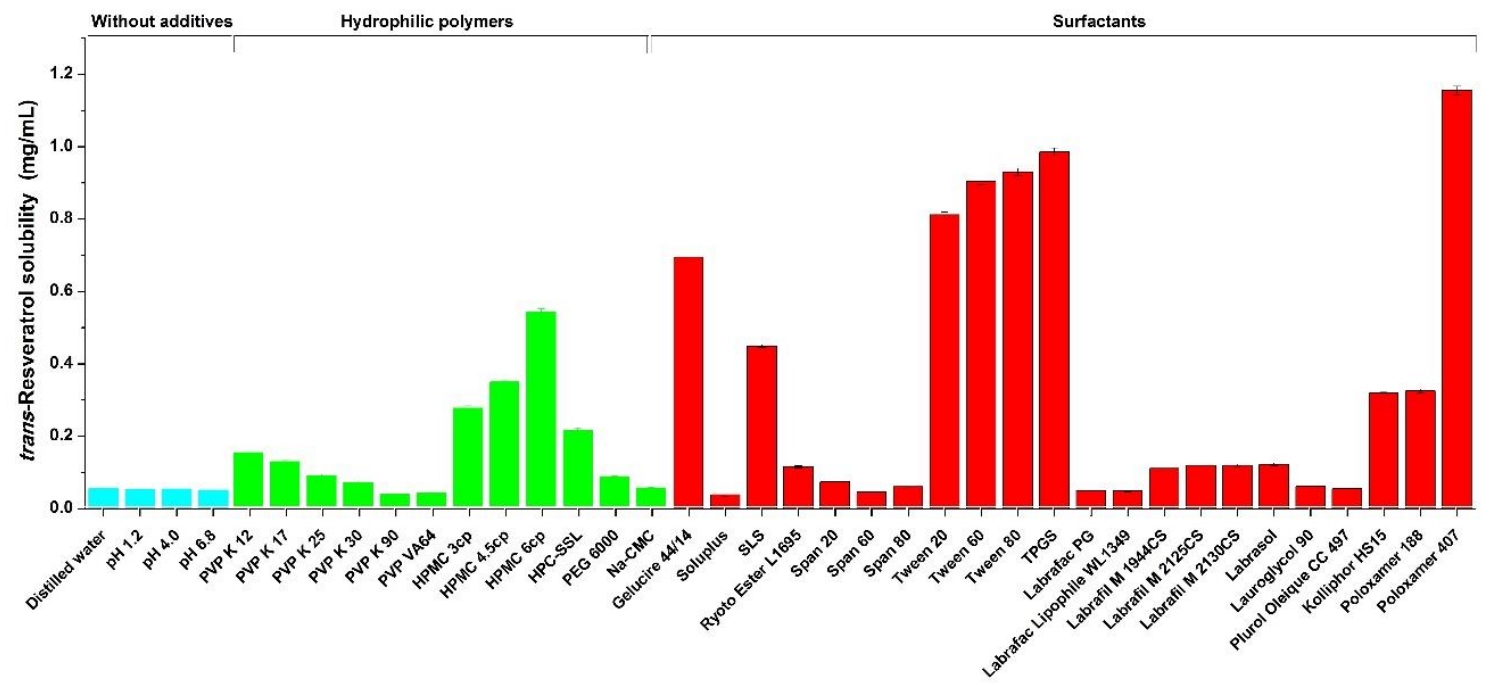

Figure 1. Solubility of trans-resveratrol in aqueous solutions containing $1 \%$ of various additives at $37^{\circ} \mathrm{C}$. Note: PVP = polyvinylpyrrolidone; HPMC = hydroxylpropylmethyl cellulose; SLS = sodium lauryl sulfate; $\mathrm{CMC}=$ sodium carboxymethylcellulose; HPC-SSL = hydroxylpropyl cellulose; TPGS $=$ D- $\alpha$-Tocopherol polyethylene glycol 1000 succinate PEG = polyethylene glycol .

\subsection{Preparation and Characterization of Trans-Resveratrol Composite Nanoparticles}

In this study, we prepared composite nanoparticles containing 1:4 and 1:5 ratios of trans-resveratrol/HPMC using a SAS process and evaluated the molecular dispersion of trans-resveratrol within composite nanoparticles based on previously reported formulations [32]. In addition, the effects of surfactants (poloxamer 407, TPGS, and gelucire 44/14) on the physicochemical properties and in vivo performance of trans-resveratrol-loaded composite nanoparticles was evaluated at a 1:4:1 ratio of trans-resveratrol/HPMC/surfactants. In our previous work, nanoparticle agglomeration was observed in composite nanoparticles with high levels of low melting point surfactants (poloxamer 407, TPGS, and gelucire 44/14) prepared using an SAS process [33-35]. As shown in Figure 2 and Table 1, micronized trans-resveratrol morphology includes needle-shaped particles with mean particle sizes of $2.6 \mu \mathrm{m}$, while trans-resveratrol-HPMC nanoparticles are spherical particles with sizes of $180-190 \mathrm{~nm}$ and specific surface areas of $60-64 \mathrm{~m}^{2} / \mathrm{g}$. No significant differences were observed between trans-resveratrol-HPMC nanoparticles composed of 1:4 and 1:5 ratios of trans-resveratrol/HPMC. However, surfactant addition to nanoparticles increased mean particle size and reduced specific surface areas. In particular, trans-resveratrol/HPMC/TPGS nanoparticles with mean particle sizes of $293.4 \mathrm{~nm}$ exhibited fusion and aggregations of nanoparticles with specific surface areas of $36.4 \mathrm{~m}^{2} / \mathrm{g}$ due to the low melting temperature of TPGS $\left(37^{\circ} \mathrm{C}\right)$. Nevertheless, mean particle sizes of all the composite nanoparticles produced were less than $300 \mathrm{~nm}$. Trans-resveratrol was successfully incorporated into composite nanoparticles and the encapsulation efficiency exceeded $97 \%$ for all formulations, indicating that trans-resveratrol was not degraded during the SAS process (Table 1). In addition, SAS process yields were above $80 \%$ for all formulations. 

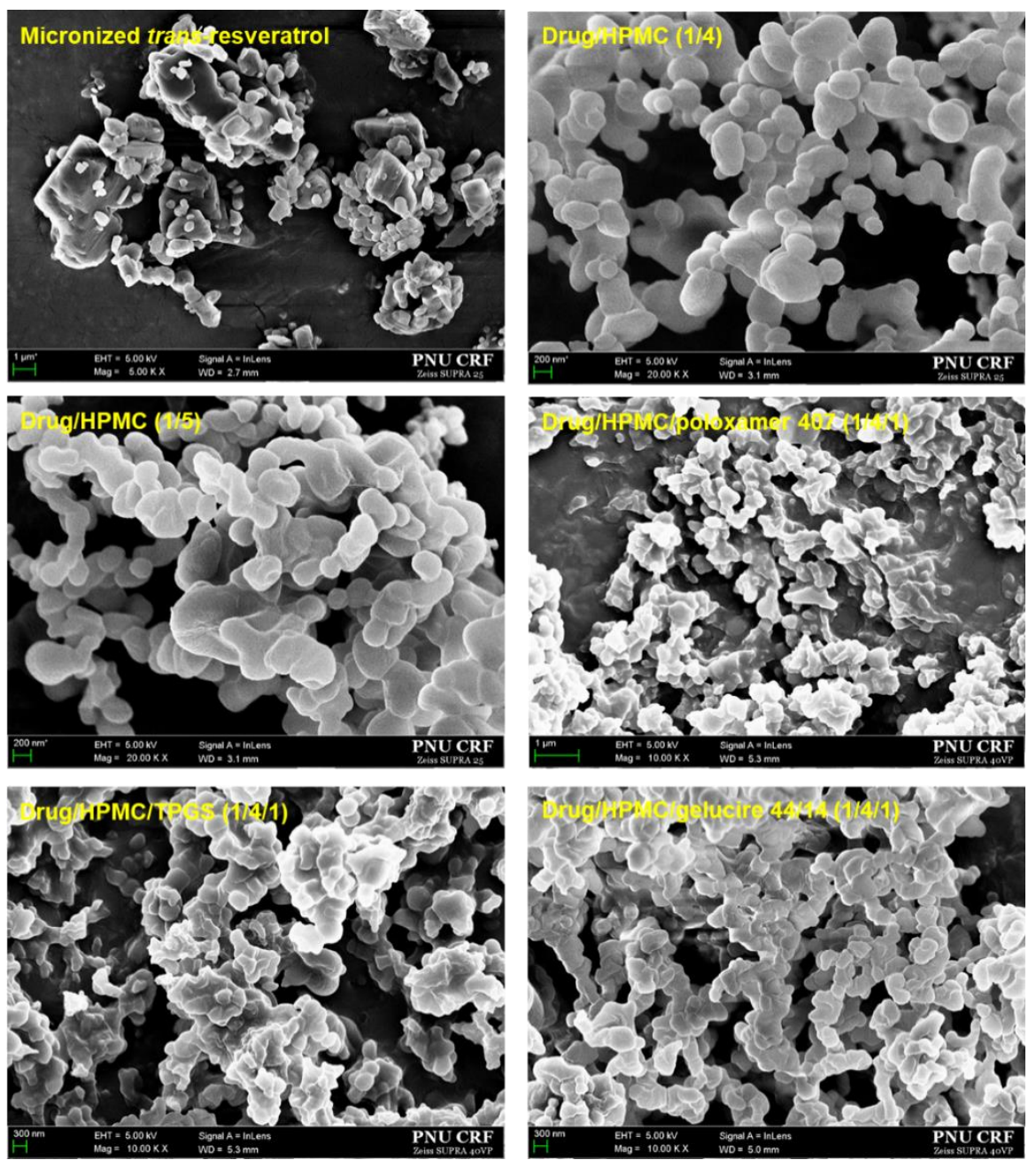

Figure 2. SEM images of trans-resveratrol composite nanoparticles.

Table 1. Composition, encapsulation efficiency, mean particle size, and specific surface area of trans-resveratrol composite nanoparticles.

\begin{tabular}{cccc}
\hline Formulation & $\begin{array}{c}\text { Encapsulation } \\
\text { Efficiency } \mathbf{( \% )}\end{array}$ & Mean Particle Size $(\mathbf{n m})$ & Specific Surface Area $\left(\mathbf{m}^{2} / \mathbf{g}\right)$ \\
\hline Micronized trans-resveratrol & - & $2631.4 \pm 203.1$ & $2.98 \pm 0.3$ \\
Drug/HPMC/poloxamer 407 & $98.9 \pm 0.6$ & $258.5 \pm 19.5$ & $40.2 \pm 1.6$ \\
Drug/HPMC/TPGS & $99.1 \pm 0.8$ & $293.4 \pm 16.9$ & $36.4 \pm 1.1$ \\
Drug/HPMC/gelucire 44/14 & $97.2 \pm 1.2$ & $291.7 \pm 15.2$ & $33.1 \pm 1.3$ \\
Drug/HPMC (1:5) & $98.2 \pm 0.9$ & $188.2 \pm 6.9$ & $60.4 \pm 2.3$ \\
Drug/HPMC (1:4) & $99.9 \pm 0.3$ & $181.5 \pm 8.5$ & $63.2 \pm 1.9$ \\
\hline
\end{tabular}

Data are expressed as the mean \pm standard deviation $(n=4)$.

The crystallinity and dispersion of trans-resveratrol in composite nanoparticles was analyzed using modulated DSC and PXRD. In DSC thermograms (Figure 3A), the melting temperature and fusion enthalpy of raw trans-resveratrol are $268.96^{\circ} \mathrm{C}$ and $270.96 \mathrm{~J} / \mathrm{g}$, respectively, in good agreement with previously reported data [36]. The complete disappearance of a single, sharp melting endotherm for trans-resveratrol was observed for composite nanoparticles, indicating that trans-resveratrol exists in an amorphous or molecularly dispersed state within composite nanoparticles. Furthermore, we also analyzed the glass transition temperature $\left(T_{\mathrm{g}}\right)$ using modulated DSC measurements. If small molecule drugs act as a plasticizer, the $T_{\mathrm{g}}$ value of the polymer should decrease with increasing drug content in polymer-drug blends. As shown in reversing heat flow versus temperature thermograms (Figure $3 \mathrm{~B}$ ), the $T_{\mathrm{g}}$ value of the composite nanoparticles decreased with increasing 
trans-resveratrol level, and all composite nanoparticles exhibited one $T_{\mathrm{g}}$ value. From these results, trans-resveratrol appears dispersed at the molecular level within the composite nanoparticles. In addition, samples of micronized trans-resveratrol and composite nanoparticles were characterized using PXRD to assess the preparation of amorphous composites of trans-resveratrol (Figure 3C). Micronized trans-resveratrol exhibited characteristic peaks at $2 \theta$, similar to previously reported results [37] However, characteristic peak patterns for trans-resveratrol were not observed for all composite nanoparticle preparations, indicating that trans-resveratrol is molecularly dispersed within composite nanoparticles.
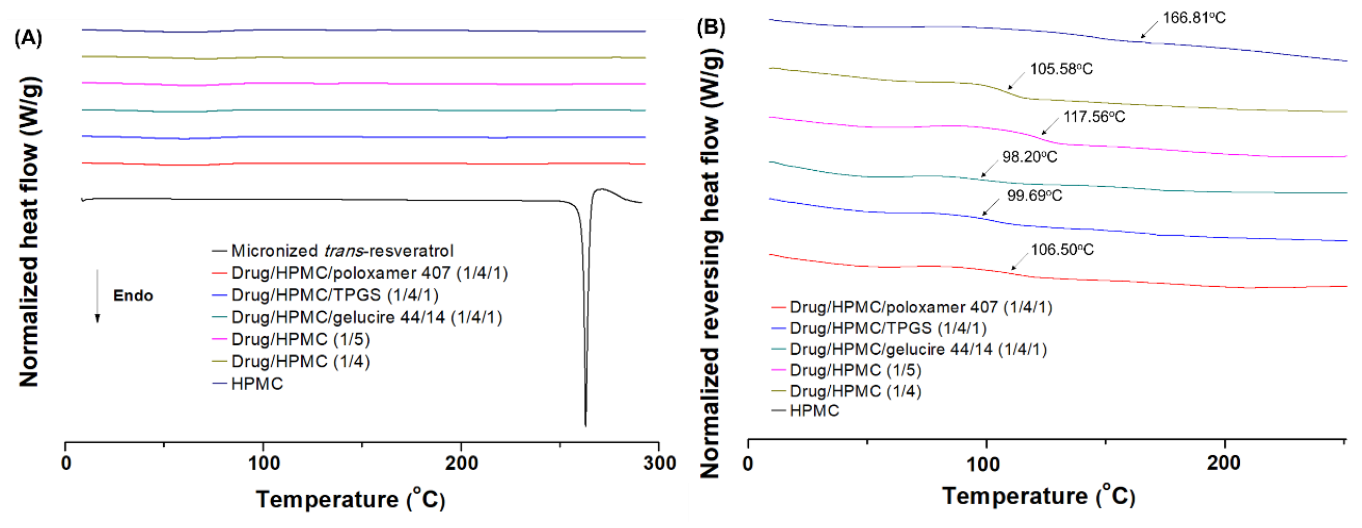

(c)

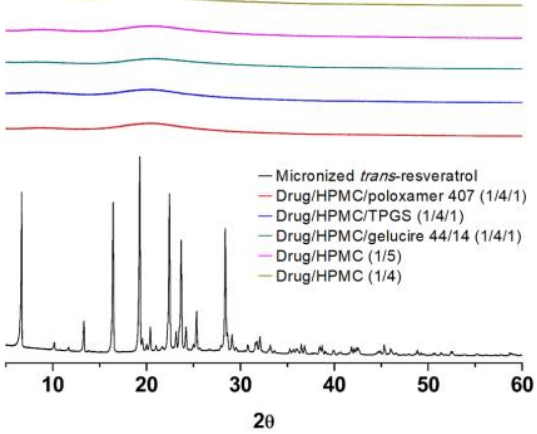

Figure 3. Differential scanning calorimetry thermograms of (A) heat flow versus temperature and (B) reversing heat flow versus temperature, and powder X-ray diffraction patterns (C) of trans-resveratrol composite nanoparticles.

The kinetic solubility of trans-resveratrol composite nanoparticles was determined in distilled water at $37^{\circ} \mathrm{C}$. As shown in Figure 4, the degree of solubility of trans-resveratrol in composite nanoparticles was dramatically increased compared to that of micronized trans-resveratrol. In particular, the solubility of trans-resveratrol/HPMC/poloxamer 407 (1:4:1) nanoparticles at $24 \mathrm{~h}$ was significantly higher ( 7.2x) than that of micronized trans-resveratrol. The solubility values of trans-resveratrol-loaded composite nanoparticles at $24 \mathrm{~h}$ as ranked by the SNK test were as follows: drug/HPMC/poloxamer 407 (1:4:1) > drug/HPMC/TPGS (1:4:1) > drug/HPMC/gelucire 44/14 (1:4:1) > drug/HPMC (1:5) = drug/HPMC (1:4) > micronized trans-resveratrol. The maximum solubility of trans-resveratrol from composite nanoparticles was rapidly reached and maintained for at least $24 \mathrm{~h}$ through high inhibition of trans-resveratrol crystallization by HPMC [32,38]. 


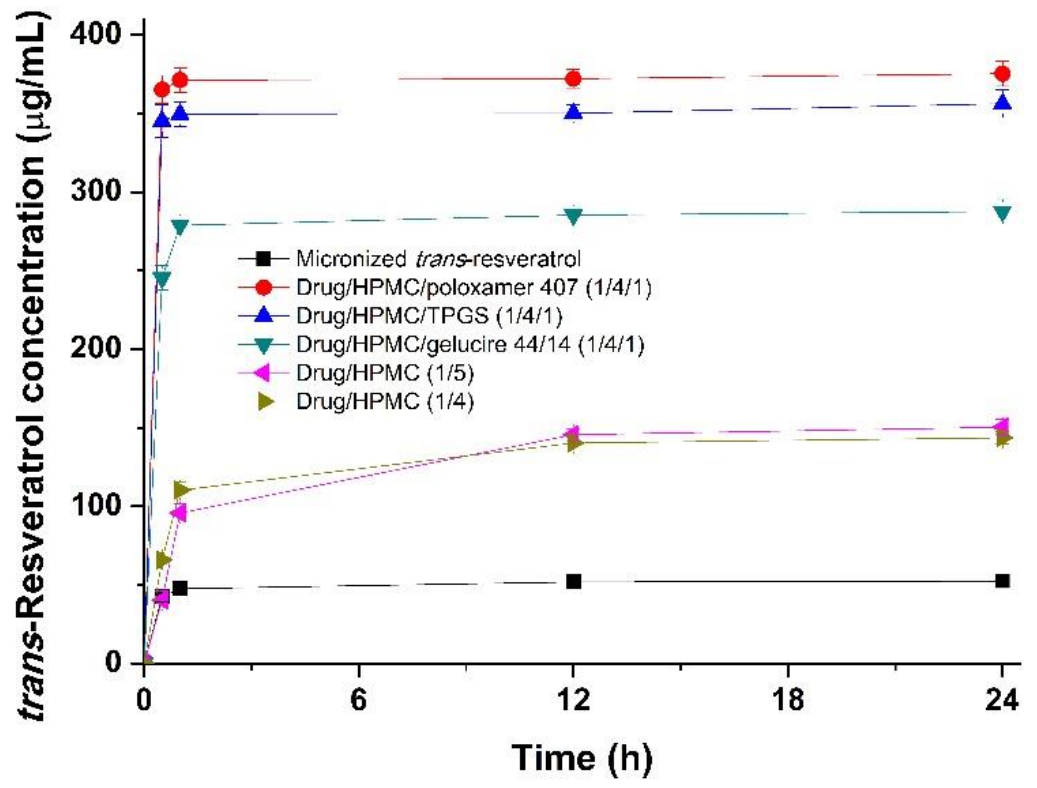

Figure 4. Kinetic solubility profiles of trans-resveratrol composite nanoparticles in distilled water at $37^{\circ} \mathrm{C}$.

\subsection{Use of Trans-Resveratrol Composite Nanoparticles for Oral Delivery}

To compare trans-resveratrol flux of different composite nanoparticles prepared by the SAS process and establish correlations between in vitro flux data and in vivo pharmacokinetic data of trans-resveratrol, in vitro flux measurements and in vivo pharmacokinetic experiments of trans-resveratrol in SD rats were carried out using the oral delivery of trans-resveratrol composite nanoparticles. As shown in Figure 5A, the concentration of trans-resveratrol from composite nanoparticles in the donor cell increased with increasing solubility of composite nanoparticles. Higher concentrations of trans-resveratrol in the receiver cell were observed by increasing the driving force of trans-resveratrol through the membrane. In addition, the concentration of trans-resveratrol over time in the donor cell indicated maximum dissolution of trans-resveratrol from the composite nanoparticles within $2 \mathrm{~min}$, indicating fast dissolution from multiple HPMC/surfactant combinations. Flux $(J)$ was obtained from the slope of the concentration of trans-resveratrol vs. time profile in the range of 30 to $240 \mathrm{~min}$ in Figure 5B, and is presented in Table 2. The system reached steady state within $30 \mathrm{~min}$ after dissolution-permeation measurements. As shown in Table 2, trans-resveratrol/HPMC/poloxamer 407 (1:4:1) nanoparticles exhibited the highest flux of $0.792 \mu \mathrm{g} / \mathrm{min} / \mathrm{cm}^{2}$, which was 3.0-fold higher than the flux of micronized trans-resveratrol. Flux ranks based on the SNK test for trans-resveratrol-loaded composite nanoparticles were as follows: drug/HPMC/poloxamer 407 (1:4:1) > drug/HPMC/TPGS $(1: 4: 1)>$ drug/HPMC/gelucire 44/14 (1:4:1) > drug/HPMC (1:5) = drug/HPMC (1:4) > micronized trans-resveratrol. The trend of increased flux of composite nanoparticles is similar to the trend for kinetic solubility of trans-resveratrol. In addition, the very fast dissolution of trans-resveratrol from HPMC/surfactant nanoparticles was observed in the donor cell.

The increased solubility and flux of trans-resveratrol by composite nanoparticles increases the oral bioavailability of trans-resveratrol [39,40]. As shown in Figure 6, HPMC/surfactant composite nanoparticles have rapid absorption rates and significantly higher exposure $4 \mathrm{~h}$ after oral administration compared to micronized trans-resveratrol. $C_{\max }$ ranks based on the SNK test for trans-resveratrol-loaded composite nanoparticles were: drug/HPMC/poloxamer 407 (1:4:1) = drug/HPMC/TPGS (1:4:1) > drug/HPMC/gelucire 44/14 (1:4:1) > drug/HPMC (1:5) = drug/HPMC (1:4) > micronized trans-resveratrol. The $A U C_{0-12 \mathrm{~h}}$ ranked by the $\mathrm{SNK}$ test for trans-resveratrol-loaded composite nanoparticles were as follows: drug/HPMC/poloxamer 407 (1:4:1) > drug/HPMC/TPGS (1:4:1) > drug/HPMC/gelucire 44/14 $(1: 4: 1)>$ drug/HPMC (1:5) = drug/HPMC (1:4) > micronized trans-resveratrol. Composition ranks for flux data, thus, agreed with ranks for $A U C_{0-12 \mathrm{~h}}$. Greater increases in $C_{\max }$ and $A U C_{0 \rightarrow 12 \mathrm{~h}}$ 
were observed for composite nanoparticles compared to micronized trans-resveratrol. In particular, $C_{\text {max }}$ and $A U C_{0 \rightarrow 12}$ h of trans-resveratrol/HPMC/poloxamer 407 (1:4:1) nanoparticles were 9.7-fold and 3.0-fold higher, respectively, than those of micronized trans-resveratrol, which may be due to the rapid metabolism of trans-resveratrol [41].
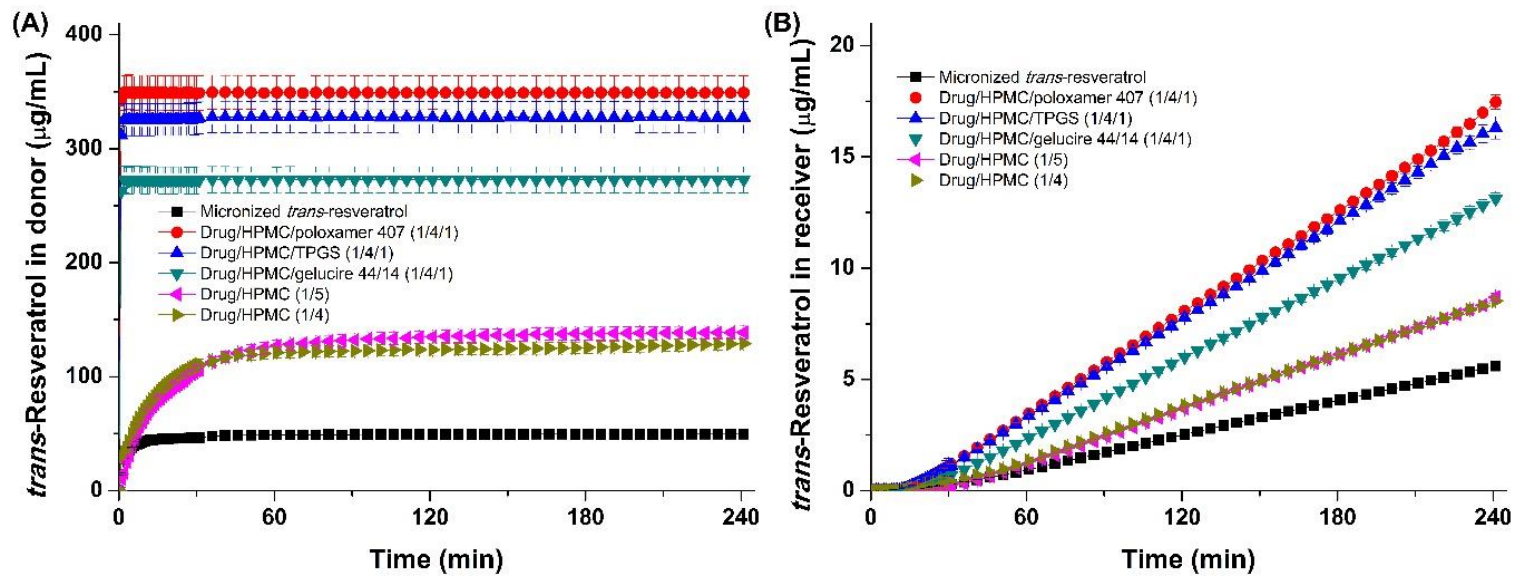

Figure 5. In vitro dissolution (A) and permeation profiles (B) of trans-resveratrol composite nanoparticles. Data are expressed as the mean \pm standard deviation $(n=4)$.

Table 2. In vitro flux data and in vivo pharmacokinetic data for trans-resveratrol composite nanoparticles.

\begin{tabular}{|c|c|c|c|c|}
\hline \multirow{2}{*}{ Formulation } & \multirow{2}{*}{$\begin{array}{l}\text { In Vitro Flux } \\
\left(\mu \mathrm{g} / \mathrm{cm}^{2} / \mathrm{min}\right)\end{array}$} & \multicolumn{3}{|c|}{ In Vivo Pharmacokinetic Data } \\
\hline & & $\begin{array}{c}\mathrm{AUC}_{0 \rightarrow 12 \mathrm{~h}} \\
\text { (ng.h/mL) }\end{array}$ & $\begin{array}{c}\mathrm{C}_{\max } \\
(\mathrm{ng} / \mathrm{mL})\end{array}$ & $\begin{array}{l}\mathrm{T}_{\max } \\
\text { (h) }\end{array}$ \\
\hline Micronized trans-resveratrol & $0.266 \pm 0.006$ & $163.4 \pm 33.1$ & $43.4 \pm 6.3$ & $1.0 \pm 0.5$ \\
\hline Drug/HPMC/poloxamer 407 & $0.792 \pm 0.013^{a, b, c, d}$ & $493.6 \pm 45.4^{\mathrm{a}, \mathrm{b}, \mathrm{c}, \mathrm{d}}$ & $420.3 \pm 63.4^{a, b, c}$ & $0.5 \pm 0.1$ \\
\hline Drug/HPMC/TPGS & $0.761 \pm 0.016^{\mathrm{a}, \mathrm{b}, \mathrm{c}}$ & $434.3 \pm 30.1^{\mathrm{a}, \mathrm{b}, \mathrm{c}}$ & $368.7 \pm 72.1^{\mathrm{a}, \mathrm{b}}$ & $0.5 \pm 0.2$ \\
\hline Drug/HPMC/gelucire 44/14 & $0.618 \pm 0.012^{a, b}$ & $365.4 \pm 45.0^{a, b}$ & $268.7 \pm 78.9^{\mathrm{a}}$ & $0.7 \pm 0.4$ \\
\hline Drug/HPMC (1:5) & $0.419 \pm 0.012^{\mathrm{a}}$ & $256.6 \pm 53.8^{\mathrm{a}}$ & $133.5 \pm 36.7$ & $0.9 \pm 0.3$ \\
\hline Drug/HPMC (1:4) & $0.409 \pm 0.004^{\mathrm{a}}$ & $245.9 \pm 76.9^{\mathrm{a}}$ & $132.2 \pm 27.3$ & $0.7 \pm 0.2$ \\
\hline
\end{tabular}

Note: ${ }^{\mathrm{a}} p<0.05$ vs. micronized trans-resveratrol; ${ }^{\mathrm{b}} p<0.05$ vs. drug/HPMC (1:5); ${ }^{\mathrm{c}} p<0.05 \mathrm{vs.} \mathrm{drug/HPMC/Gelucire}$ $44 / 14$ (1:4:1); ${ }^{\mathrm{d}} p<0.05$ vs. drug/HPMC/TPGS (1:4:1). Data are expressed as the mean \pm standard deviation $(n=4$ or 6$)$. $A U C_{0 \rightarrow 12 \mathrm{~h}}$, the area under the plasma concentration versus time curve; $C$ max, the maximum plasma concentration of trans-resveratrol; $T_{\max }$, the time required to reach $C_{\max }$.

To further investigate correlations between in vitro flux data and in vivo pharmacokinetic data for trans-resveratrol, linear regression analysis was used. A good correlation was observed between relative in vitro flux, relative in vivo $C_{\max }$, and in vivo $A U C_{0 \rightarrow 12 \mathrm{~h}}$ of composite nanoparticles and micronized trans-resveratrol $\left(R^{2}>0.989\right)$. In fact, in vitro flux data reasonably represent in vivo pharmacokinetic data of trans-resveratrol, as previously reported for other poorly water-soluble compounds [33-35]. Trans-resveratrol/HPMC/poloxamer 407 (1:4:1) nanoparticles show 3.0-fold higher flux enhancement and 9.7-fold higher $C_{\max }$ compared to micronized trans-resveratrol. However, the3.0-fold in vivo increase in $A U C_{0 \rightarrow 12 \mathrm{~h}}$ for trans-resveratrol/HPMC/poloxamer 407 (1:4:1) nanoparticles relative to micronized trans-resveratrol more closely follows the in vitro flux enhancement. Similar to a previously reported method [28], we performed regression analysis between the total amount of trans-resveratrol absorbed at $240 \mathrm{~min}$ in flux measurements and in in vivo $A U C_{0-12} \mathrm{~h}$. At $240 \mathrm{~min}$, the amounts of permeated trans-resveratrol in the receiver cell were $89.6 \pm 2.0 \mu \mathrm{g}$ for micronized trans-resveratrol, $136.4 \pm 2.2 \mu \mathrm{g}$ for drug/HPMC (1:4), $139.1 \pm 2.9 \mu \mathrm{g}$ for drug/HPMC (1:5), $209.7 \pm 4.2 \mu \mathrm{g}$ for drug/HPMC/gelucire 44/14 (1:4:1), $260.9 \pm 8.2 \mu \mathrm{g}$ for drug/HPMC/TPGS (1:4:1), and 279.5 $\pm 5.3 \mu \mathrm{g}$ for drug/HPMC/poloxamer 407 (1:4:1), with the same ranks observed for in vivo $A U C_{0 \rightarrow 12} \mathrm{~h}$. As shown in Figure $7 \mathrm{C}$, there is good positive linear correlation between the total amount of trans-resveratrol absorbed at $240 \mathrm{~min}$ in flux 
measurements and in vivo $A U C_{0 \rightarrow 12} \mathrm{~h}$ data obtained from plasma concentration-time profiles in rats $\left(R^{2}>0.990\right)$. In fact, in vitro flux data can predict the in vivo pharmacokinetic data for trans-resveratrol. In addition, experimental conditions for flux measurements can be modified to establish proportional linear relationships between in vitro and in vivo data.

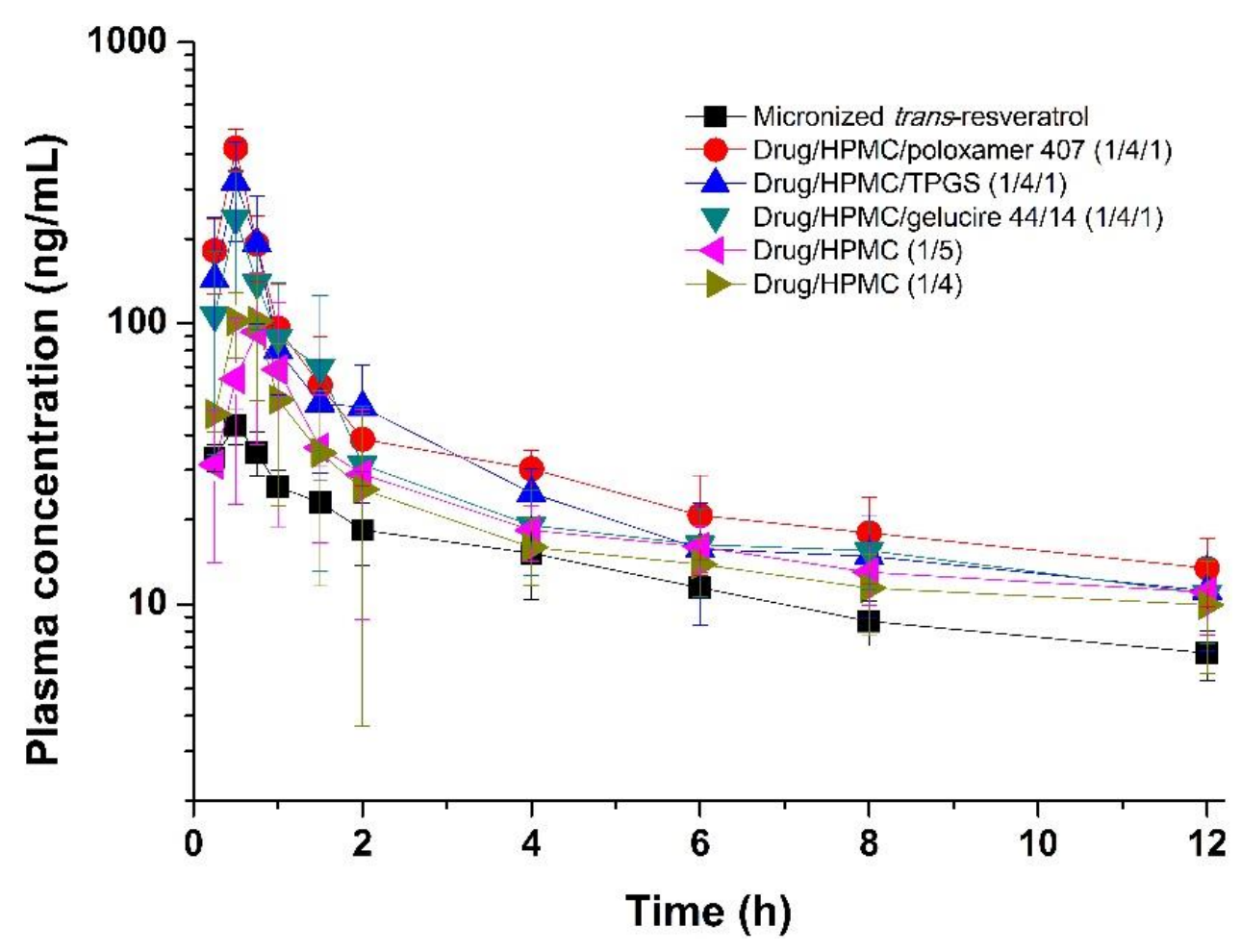

Figure 6. Plasma concentration versus time profiles of trans-resveratrol after oral administration of composite nanoparticles to Sprague-Dawley (SD) rats. Data are expressed as the mean \pm standard deviation $(n=6)$.

Generally, the oral absorption of poorly water-soluble compounds can be accounted for by including the solubilization and dissolution processes as rate-limiting steps [42]. In this study, we demonstrated that a highly supersaturated solution generated using HPMC/surfactant nanoparticles is able to diffuse trans-resveratrol through membranes and enhance the flux of trans-resveratrol to receiver cells in in vitro flux measurement studies. Consequently, the enhanced flux of trans-resveratrol induces higher driving forces in the gastrointestinal epithelial membrane, resulting in enhanced oral delivery of trans-resveratrol in in vivo pharmacokinetic studies of rats [43,44]. Taken together, our results suggest that trans-resveratrol-loaded composite nanoparticles prepared using an SAS process are useful for orally delivering trans-resveratrol in a manner that allows fast absorption in the initial phase, resulting in higher overall exposure. 

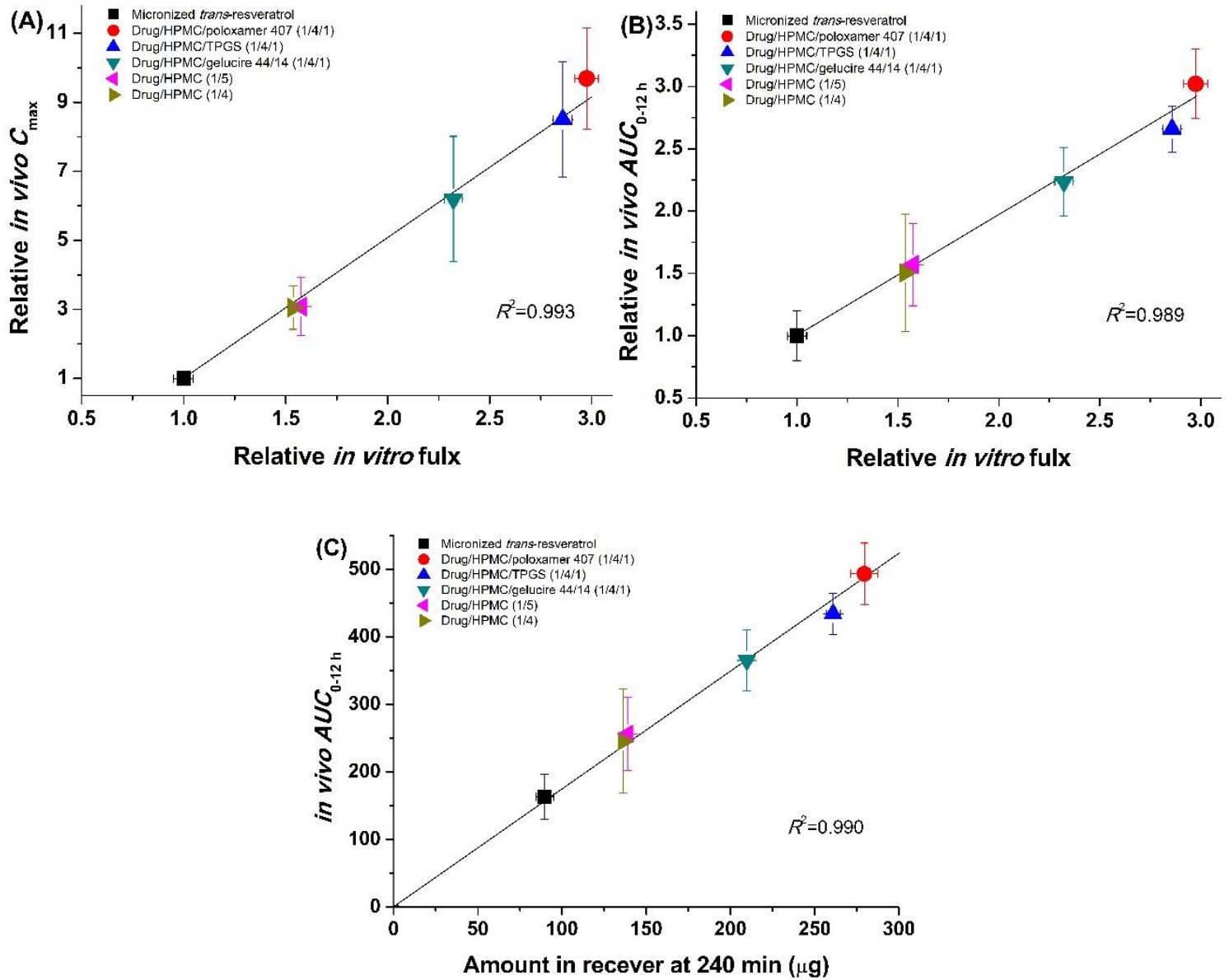

Figure 7. Correlations between in vitro flux data and in vivo pharmacokinetic data of trans-resveratrol: (A) in vitro flux vs. in vivo $C_{\max }$ of composite nanoparticles relative to micronized trans-resveratrol; (B) in vitro flux vs. in vivo $A U C_{0-12} \mathrm{~h}$ of composite nanoparticles relative to micronized trans-resveratrol;

(C) total absorbed trans-resveratrol at $240 \mathrm{~min}$ in flux measurements vs. in vivo $A U C_{0 \rightarrow 12 \mathrm{~h}}$.

\subsection{Utilization of Trans-Resveratrol Composite Nanoparticles for Skin Delivery}

To investigate the application of trans-resveratrol-loaded composite nanoparticles for skin delivery, we performed ex vivo permeation studies using skin from rats. The cumulative amount of permeated trans-resveratrol $(Q)$ per unit area of skin $\left(\mu \mathrm{g} / \mathrm{cm}^{2}\right)$ was determined using HPLC analysis. To calculate flux, defined as the rate of diffusion of a substance through a permeable membrane, $Q$ versus time profiles were generated (Figure 8). The steady state flux $\left(J_{\mathrm{ss}}\right)$ of trans-resveratrol was calculated based on the slope of the linear portion of the $Q$ versus time profiles. The permeation of trans-resveratrol-loaded composite nanoparticles was higher compared to permeation of micronized trans-resveratrol (Figure 8). In particular, the steady state flux $\left(J_{\text {ss }}\right)$ of trans-resveratrol/HPMC/poloxamer 407 (1:4:1) nanoparticles was significantly higher ( 14.9-fold) than that of micronized trans-resveratrol. The steady state flux $\left(J_{\mathrm{ss}}\right)$ ranks for trans-resveratrol-loaded composite nanoparticles based on the SNK test are: drug/HPMC/poloxamer 407 (1:4:1) > drug/HPMC/TPGS (1:4:1) > drug/HPMC/gelucire 44/14 (1:4:1) > drug/HPMC (1:5) = drug/HPMC (1:4) > micronized trans-resveratrol. Skin penetration of trans-resveratrol has been confirmed in multiple studies $[7,10,11]$. The enhancement of solubility and dissolution rates of trans-resveratrol by composite nanoparticles produced using the SAS process has been shown to enhance trans-resveratrol penetration. Interestingly, the steady state flux $\left(J_{\mathrm{ss}}\right)$ of trans-resveratrol from composite nanoparticles containing poloxamer 407 and TPGS was much higher than that of composite nanoparticles containing gelucire 44/14, with approximately 2.2- and 1.9-fold increases, respectively, compared to micronized trans-resveratrol. This increase in skin 
permeation is likely a result of the penetration-enhancing properties of surfactants, such as poloxamer 407 and TPGS $[45,46]$. Surfactants can potentially solubilize stratum corneum lipids, and thus enhance penetration $[47,48]$. Surfactants have well-known effects on permeability characteristics of several biological membranes, including membranes in the skin, and thus can enhance the penetration of skin by other compounds present in formulations [49]. In addition, the enhanced permeation may be due to the permeation of solute-containing nanoparticles through shunt routes, such as hair follicles [50]. However, further mechanistic studies are needed of trans-resveratrol-loaded composite nanoparticles.

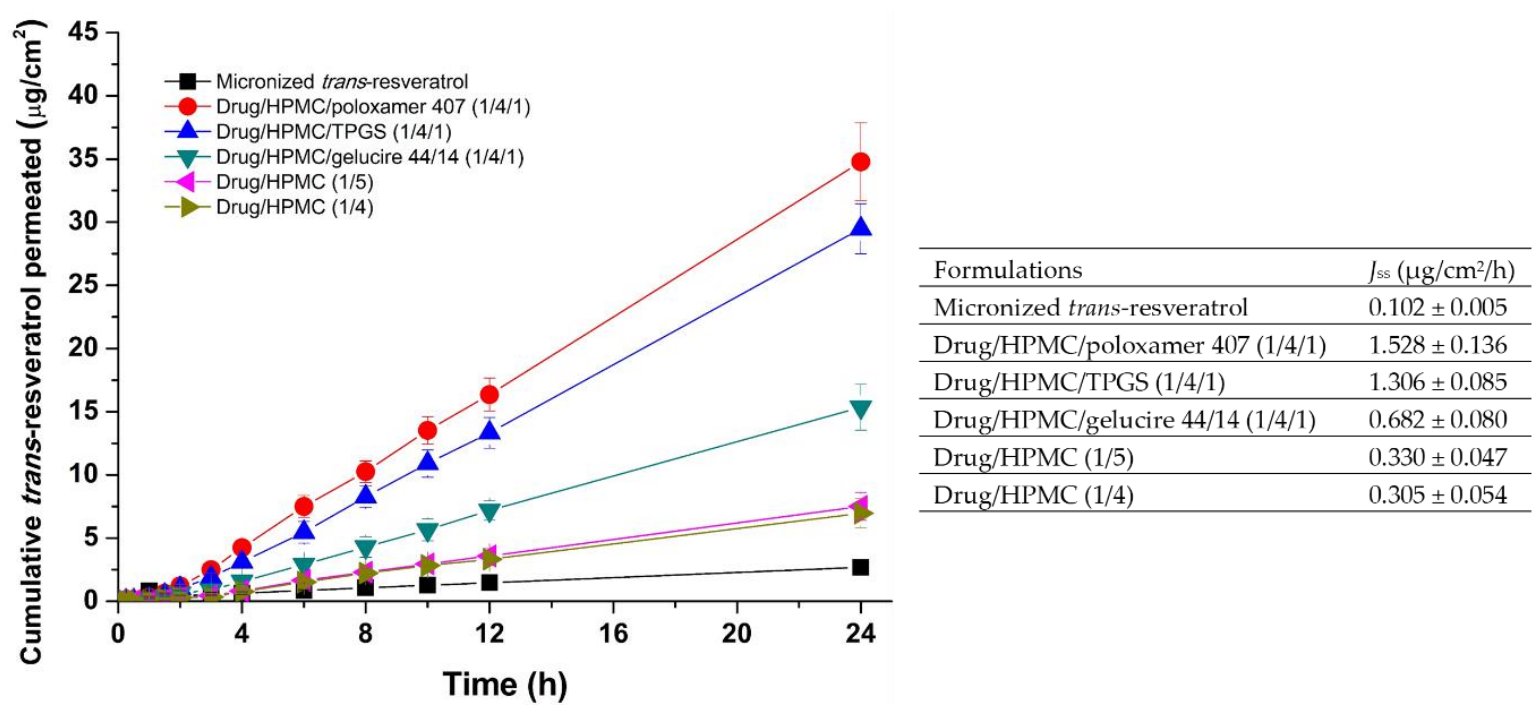

Figure 8. Cumulative ex vivo skin permeation profiles and flux $\left(J_{\mathrm{ss}}\right)$ data for trans-resveratrol composite nanoparticles. Data are presented as means \pm standard deviation $(n=6)$.

\section{Conclusions}

In our study, we designed HPMC/surfactants nanoparticles using the supercritical antisolvent (SAS) process in order to increase solubility and dissolution properties of trans-resveratrol for effective oral and skin delivery. Spherical composite nanoparticles with a mean size smaller than $300 \mathrm{~nm}$ were successfully produced using an SAS process. Among the formulations tested, trans-resveratrol/HPMC/poloxamer 407 (1:4:1) nanoparticles show the highest flux of $0.792 \mu \mathrm{g} / \mathrm{min} / \mathrm{cm}^{-2}$, exhibit rapid absorption, and have significantly higher exposure $4 \mathrm{~h}$ after oral administration than micronized trans-resveratrol. Good correlations between in vitro flux and in vivo pharmacokinetic data were also observed. The increased solubility and flux of trans-resveratrol generated using HPMC/surfactant nanoparticles increased driving forces on the gastrointestinal epithelial membrane and rat skin, resulting in enhanced oral and skin delivery of trans-resveratrol. HPMC/surfactant nanoparticles produced by the SAS process are, therefore, promising formulations enhancing trans-resveratrol absorption via oral administration for use in healthcare products, as well for skin application of cosmetic products.

Author Contributions: Conceptualization, E.-S.H., J.-S.K., S.-J.H., and M.-S.K.; formal analysis, E.-S.H., W.-Y.S., S.-K.L., J.-S.J., J.-S.K., I.-h.B., D.H.C., H.P., and M.-S.K.; funding acquisition, M.-S.K.; investigation, E.-S.H., W.-Y.S., S.-K.L., and M.-S.K.; methodology, E.-S.H., W.-Y.S., S.-K.L., J.-S.J., J.-S.K., I.-h.B., D.H.C., H.P., and M.-S.K.; software, D.H.C., S.-J.H., and M.-S.K.; supervision, M.-S.K.; validation, E.-S.H.; writing-original draft, E.-S.H. and M.-S.K.; writing-review and editing, J.-S.K., I.-h.B., D.H.C., H.P., S.-J.H., and M.-S.K.

Funding: This research was supported by Basic Science Research Program through the National Research Foundation of Korea (NRF), funded by the Ministry of Science, ICT, and Future Planning (NRF- 2017R1C1B1006483).

Conflicts of Interest: The authors declare no conflict of interest. 


\section{References}

1. Amri, A.; Chaumeil, J.C.; Sfar, S.; Charrueau, C. Administration of resveratrol: What formulation solutions to bioavailability limitations? J. Control. Release 2012, 158, 182-193. [CrossRef] [PubMed]

2. Zhao, Y.; Shi, M.; Ye, J.-H.; Zheng, X.-Q.; Lu, J.-L.; Liang, Y.-R. Photo-induced chemical reaction of trans-resveratrol. Food Chem. 2015, 171, 137-143. [CrossRef] [PubMed]

3. Ramírez-Garza, S.L.; Laveriano-Santos, E.P.; Marhuenda-Muñoz, M.; Storniolo, C.E.; Tresserra-Rimbau, A.; Vallverdú-Queralt, A.; Lamuela-Raventós, R.M. Health Effects of Resveratrol: Results from Human Intervention Trials. Nutrients 2018, 10, 1892. [CrossRef] [PubMed]

4. Na, J.-I.; Shin, J.-W.; Choi, H.-R.; Kwon, S.-H.; Park, K.-C. Resveratrol as a Multifunctional Topical Hypopigmenting Agent. Int. J. Mol. Sci. 2019, 20, 956. [CrossRef]

5. Fonseca, J.; Moradi, F.; Valente, A.J.F.; Stuart, J.A. Oxygen and Glucose Levels in Cell Culture Media Determine Resveratrol's Effects on Growth, Hydrogen Peroxide Production, and Mitochondrial Dynamics. Antioxidants 2018, 7, 157. [CrossRef]

6. Chimento, A.; De Amicis, F.; Sirianni, R.; Sinicropi, M.S.; Puoci, F.; Casaburi, I.; Saturnino, C.; Pezzi, V. Progress to Improve Oral Bioavailability and Beneficial Effects of Resveratrol. Int. J. Mol. Sci. 2019, 20, 1381. [CrossRef]

7. Marier, J.F.; Vachon, P.; Gritsas, A.; Zhang, J.; Moreau, J.P.; Ducharme, M.P. Metabolism and disposition of resveratrol in rats: Extent of absorption, glucuronidation, and enterohepatic recirculation evidenced by a linked-rat model. J. Pharmacol. Exp. Ther. 2002, 302, 369-373. [CrossRef]

8. Berman, A.Y.; Motechin, R.A.; Wiesenfeld, M.Y.; Holz, M.K. The therapeutic potential of resveratrol: A review of clinical trials. Npj Precis. Oncol. 2017, 1, 35. [CrossRef]

9. Walle, T. Bioavailability of resveratrol. Ann. N. Y. Acad. Sci. 2011, 1215, 9-15. [CrossRef]

10. Mamadou, G.; Charrueau, C.; Dairou, J.; Nzouzi, N.L.; Eto, B.; Ponchel, G. Increased intestinal permeation and modulation of presystemic metabolism of resveratrol formulated into self-emulsifying drug delivery systems. Int. J. Pharm. 2017, 521, 150-155. [CrossRef]

11. Intagliata, S.; Modica, M.N.; Santagati, L.M.; Montenegro, L. Strategies to Improve Resveratrol Systemic and Topical Bioavailability: An Update. Antioxidants 2019, 8, 244. [CrossRef] [PubMed]

12. Hajjar, B.; Zier, K.-I.; Khalid, N.; Azarmi, S.; Löbenberg, R. Evaluation of a microemulsion-based gel formulation for topical drug delivery of diclofenac sodium. J. Pharm. Investig. 2018, 48, 351-362. [CrossRef]

13. Jadhav, P.; Bothiraja, C.; Pawar, A. Resveratrol-piperine loaded mixed micelles: Formulation, characterization, bioavailability, safety and in vitro anticancer activity. RSC Adv. 2016, 6, 112795-112805. [CrossRef]

14. Zu, Y.; Zhang, Y.; Wang, W.; Zhao, X.; Han, X.; Wang, K.; Ge, Y. Preparation and in vitro/in vivo evaluation of resveratrol-loaded carboxymethyl chitosan nanoparticles. Drug Deliv. 2016, 23, 981-991. [CrossRef]

15. Dhakar, N.K.; Matencio, A.; Caldera, F.; Argenziano, M.; Cavalli, R.; Dianzani, C.; Zanetti, M.; López-Nicolás, J.M.; Trotta, F. Comparative Evaluation of Solubility, Cytotoxicity and Photostability Studies of Resveratrol and Oxyresveratrol Loaded Nanosponges. Pharmaceutics 2019, 11, 545. [CrossRef]

16. Gartziandia, O.; Lasa, A.; Pedraz, J.L.; Miranda, J.; Portillo, M.P.; Igartua, M.; Hernández, R.M. Preparation and Characterization of Resveratrol Loaded Pectin/Alginate Blend Gastro-Resistant Microparticles. Molecules 2018, 23, 1886. [CrossRef]

17. Shimojo, A.A.M.; Fernandes, A.R.V.; Ferreira, N.R.E.; Sanchez-Lopez, E.; Santana, M.H.A.; Souto, E.B. Evaluation of the Influence of Process Parameters on the Properties of Resveratrol-Loaded NLC Using $2^{2}$ Full Factorial Design. Antioxidants 2019, 8, 272. [CrossRef]

18. Aguiar, G.P.S.; Arcari, B.D.; Chaves, L.M.P.C.; Magro, C.D.; Boschetto, D.L.; Piato, A.L.; Lanza, M.; Oliveira, J.V. Micronization of trans-resveratrol by supercritical fluid: Dissolution, solubility and in vitro antioxidant activity. Ind. Crops Prod. 2018, 112, 1-5. [CrossRef]

19. Calvo-Castro, L.A.; Schiborr, C.; David, F.; Ehrt, H.; Voggel, J.; Sus, N.; Behnam, D.; Bosy-Westphal, A.; Frank, J. The oral bioavailability of trans-resveratrol from a grapevine-shoot extract in healthy humans is significantly increased by micellar solubilization. Mol. Nutr. Food Res. 2018, 62, 1701057. [CrossRef]

20. Spogli, R.; Bastianini, M.; Ragonese, F.; Iannitti, R.G.; Monarca, L.; Bastioli, F.; Nakashidze, I.; Brecchia, G.; Menchetti, L.; Codini, M.; et al. Solid dispersion of resveratrol supported on magnesium dihydroxide (resv@mdh) microparticles improves oral bioavailability. Nutrients 2018, 10, 1925. [CrossRef] 
21. He, H.; Zhang, Q.; Wang, J.-R.; Mei, X. Structure, physicochemical properties and pharmacokinetics of resveratrol and piperine cocrystals. CrystEngComm 2017, 19, 6154-6163. [CrossRef]

22. Singh, D.; Bedi, N.; Tiwary, A.K. Enhancing solubility of poorly aqueous soluble drugs: Critical appraisal of techniques. J. Pharm. Investig. 2018, 48, 509-526. [CrossRef]

23. Ma, X.; Williams, R.O., III. Polymeric nanomedicines for poorly soluble drugs in oral delivery systems: An update. J. Pharm. Investig. 2018, 48, 61-75.

24. Abuzar, S.M.; Hyun, S.-M.; Kim, J.-H.; Park, H.J.; Kim, M.-S.; Park, J.-S.; Hwang, S.-J. Enhancing the solubility and bioavailability of poorly water-soluble drugs using supercritical antisolvent (SAS) process. Int. J. Pharm. 2018, 538, 1-13. [CrossRef] [PubMed]

25. Hu, K.; McClements, D.J. Fabrication of biopolymer nanoparticles by antisolvent precipitation and electrostatic deposition: Zein-alginate core/shell nanoparticles. Food Hydrocoll. 2015, 44, 101-108. [CrossRef]

26. Ha, E.-S.; Kim, J.-S.; Lee, S.-K.; Sim, W.-Y.; Jeong, J.-S.; Kim, M.S. Solubility and modeling of telmisartan in binary solvent mixtures of dichloromethane and (methanol, ethanol, $n$-propanol, or $n$-butanol) and its application to the preparation of nanoparticles using the supercritical antisolvent technique. J. Mol. Liq. 2019, 295, 111710. [CrossRef]

27. Ha, E.-S.; Kim, J.-S.; Lee, S.-K.; Sim, W.-Y.; Jeong, J.-S.; Kim, M.S. Equilibrium solubility and solute-solvent interactions of carvedilol (Form I) in twelve mono solvents and its application for supercritical antisolvent precipitation. J. Mol. Liq. 2019, 294, 111622. [CrossRef]

28. Tsinman, K.; Tsinman, O.; Lingamaneni, R.; Zhu, S.; Riebesehl, B.; Grandeury, A.; Juhnke, M.; Van Eerdenbrugh, B. Ranking Itraconazole formulations based on the flux through artificial lipophilic membrane. Pharm. Res. 2018, 35, 161. [CrossRef]

29. Das, S.; $\mathrm{Ng}, \mathrm{K} . \mathrm{Y}$. Quantification of trans-resveratrol in rat plasma by a simple and sensitive high performance liquid chromatography method and its application in pre-clinical study. J. Liq. Chromatogr. Relat. Technol. 2011, 34, 1399-1414. [CrossRef]

30. Alonso, C.; Martı, M.; Barba, C.; Carrer, V.; Rubio, L.; Coderch, L. Skin permeation and antioxidant efficacy of topically applied resveratrol. Arch. Dermatol. Res. 2017, 309, 423-431. [CrossRef]

31. Zupančič, Š.; Lavrič, Z.; Kristl, J. Stability and solubility of trans-resveratrol are strongly influenced by $\mathrm{pH}$ and temperature. Euro. J. Pharm. Biopharm. 2015, 93, 196-204. [CrossRef] [PubMed]

32. Wegiel, L.A.; Mosquera-Giraldo, L.I.; Mauer, L.J.; Edgar, K.J.; Taylor, L.S. Phase Behavior of Resveratrol Solid Dispersions Upon Addition to Aqueous media. Pharm. Res. 2015, 32, 3324-3337. [CrossRef] [PubMed]

33. Ha, E.-S.; Choo, G.-H.; Baek, I.-H.; Kim, M.-S. Formulation, Characterization, and in Vivo Evaluation of Celecoxib-PVP Solid Dispersion Nanoparticles Using Supercritical Antisolvent Process. Molecules 2014, 19, 20325-20339. [CrossRef] [PubMed]

34. Kim, M.-S.; Ha, E.-S.; Kim, J.-S.; Baek, I.; Yoo, J.-W.; Jung, Y.; Moon, H.R. Development of megestrol acetate solid dispersion nanoparticles for enhanced oral delivery by using a supercritical antisolvent process. Drug Des. Dev. Ther. 2015, 9, 4269-4277. [CrossRef]

35. Ha, E.S.; Choo, G.H.; Baek, I.H.; Kim, J.S.; Cho, W.; Jung, Y.S.; Jin, S.E.; Hwang, S.J.; Kim, M.S. Dissolution and bioavailability of lercanidipine-hydroxypropylmethyl cellulose nanoparticles with surfactant. Int. J. Biol. Macromol. 2015, 72, 188-222. [CrossRef]

36. Ansari, K.A.; Vavia, P.R.; Trotta, F.; Cavalli, R. Cyclodextrin-Based Nanosponges for Delivery of Resveratrol: In Vitro Characterisation, Stability, Cytotoxicity and Permeation Study. AAPS PharmSciTech 2011, 12, $279-286$. [CrossRef]

37. Aguiar, G.P.S.; Boschetto, D.L.; Chaves, L.M.P.C.; Arcari, B.D.; Piato, A.L.; Oliveira, J.V.; Lanza, M. Trans-resveratrol micronization by SEDS technique. Ind. Crops Prod. 2016, 89, 350-355. [CrossRef]

38. Liu, X.; Feng, X.; Williams, R.O., III; Zhang, F. Characterization of amorphous solid dispersions. J. Pharm. Investig. 2018, 48, 19-41. [CrossRef]

39. Chang, C.W.; Wong, C.Y.; Wu, Y.T.; Hsu, M.C. Development of a solid dispersion system for improving the oral bioavailability of resveratrol in rats. Eur. J. Drug Metab. Pharmacokinet. 2017, 42, 239-249. [CrossRef]

40. Singh, S.K.; Makadia, V.; Sharma, S.; Rashid, M.; Shahi, S.; Mishra, P.R.; Wahajuddin, M.; Gayen, J.R. Preparation and in-vitro/in-vivo characterization of trans-resveratrol nanocrystals for oral administration. Drug Deliv. Transl. Res. 2017, 7, 395-407. [CrossRef] 
41. Maier-Salamon, A.; Hagenauer, B.; Wirth, M.; Gabor, F.; Szekeres, T.; Jager, W. Increased transport of resveratrol across monolayers of the human intestinal Caco-2 cells is mediated by inhibition and saturation of metabolites. Pharm. Res. 2006, 23, 2107-2115. [CrossRef] [PubMed]

42. Ahsan, M.N.; Verma, P.R.P. Enhancement of in vitro dissolution and pharmacodynamic potential of olanzapine using solid SNEDDS. J. Pharm. Investig. 2018, 48, 269-278. [CrossRef]

43. Goo, B.; Sim, W.-Y.; Ha, E.-S.; Kim, M.-S.; Cho, C.-W.; Hwang, S.-J. Preparation of Spray-dried Emulsion of Sirolimus for Enhanced Oral Bioavailability. Bull. Korean Chem. Soc. 2018, 39, 1215-1218. [CrossRef]

44. Baek, I.H.; Kim, M.S. Improved supersaturation and oral absorption of dutasteride by amorphous solid dispersions. Chem. Pharm. Bull. 2012, 60, 1468-1473. [CrossRef] [PubMed]

45. Yang, C.; Wu, T.; Qi, Y.; Zhang, Z. Recent advances in the application of vitamin E TPGS for drug delivery. Theranostics 2018, 8, 464-485. [CrossRef]

46. Herpin, M.J.; Smyth, H.D.C. Super-heated aqueous particle engineering (SHAPE): A novel method for the micronization of poorly water soluble drugs. J. Pharm. Investig. 2018, 48, 135-142. [CrossRef]

47. Som, I.; Bhatia, K.; Yasir, M. Status of surfactants as penetration enhancers in transdermal drug delivery. J. Pharm. Bioallied Sci. 2012, 4, 2-9.

48. Rastogi, V.; Yadav, P.; Verma, N.; Verma, A. Preparation and characterization of transdermal mediated microemulsion delivery of T4 bacteriophages against E.coli bacteria: A novel anti-microbial approach. J. Pharm. Investig. 2018, 48, 394-407. [CrossRef]

49. Kim, J.-S.; Kim, M.-S.; Baek, I.-H. Enhanced Bioavailability of Tadalafil after Intranasal Administration in Beagle Dogs. Pharmaceutics 2018, 10, 187. [CrossRef]

50. Teichmann, A.; Otberg, N.; Jacobi, U.; Sterry, W.; Lademann, J. Follicular penetration: Development of a method to block the follicles selectively against the penetration of topically applied substances. Skin Pharmacol. Physiol. 2006, 19, 216-223. [CrossRef]

(C) 2019 by the authors. Licensee MDPI, Basel, Switzerland. This article is an open access article distributed under the terms and conditions of the Creative Commons Attribution (CC BY) license (http://creativecommons.org/licenses/by/4.0/). 